\title{
Araruta, seu beneficiamento e utilização em preparações gastronômicas
}

\author{
Arrowroot, its processing and use in gastronomic preparations \\ Arrowroot, su procesamiento y uso en preparaciones gastronómicas
}

Recebido: 03/11/2021 | Revisado: 12/11/2021 | Aceito: 18/11/2021 | Publicado: 25811/2021

\author{
Marciana Silva Araújo \\ ORCID: https://orcid.org/0000-0003-2378-2888 \\ Universidade Federal do Paraná, Brasil \\ E-mail: araujomarciana3@gmail.com \\ Luana Cavalcante Gonçalves da Silva \\ ORCID: https://orcid.org/0000-0003-3351-7519 \\ Universidade Federal do Ceará, Brasil \\ E-mail: luanacavalcantegs@gmail.com \\ Vinícius Quintino Lavor Andrade \\ ORCID: https://orcid.org/0000-0002-8049-1449 \\ Universidade Federal do Ceará, Brasil \\ E-mail: viniuslavor@gmail.com \\ Alessandra Pinheiro de Góes Carneiro \\ ORCID: https://orcid.org/0000-0001-5784-3808 \\ Universidade Federal do Ceará, Brasil \\ E-mail: alessandra.carneiro@ufc.br \\ Eveline de Alencar Costa \\ ORCID: https://orcid.org/0000-0002-2310-9880 \\ Universidade Federal do Ceará, Brasil \\ E-mail: evelinedealencar@ufc.br \\ Luis Eduardo Sobral Fernandes \\ ORCID: https://orcid.org/0000-0002-3117-5319 \\ Universidade Federal do Ceará, Brasil \\ E-mail: luiseduardo@cetra.org.br
}

\begin{abstract}
Resumo
O presente trabalho teve como objetivo caracterizar a parte botânica da araruta (Maranta arundinacea L.), por meio de uma revisão bibliográfica, e descrever o beneficiamento da fécula e de três diferentes classificações de farinhas, sendo elas: amarela, branca e integral produzidas em uma comunidade em Trairi, Ceará. Foram descritas as características das formas de reflorestação da araruta, a qual carrega valor cultural, e suas formas de consumo e aplicações. Além disso, foi feito um apanhado da composição centesimal da fécula da araruta comparada aos outros tipos de amidos, mostrando seu grande potencial para o uso em preparações gastronômicas. Deu-se ênfase em duas preparações: biscoito de araruta com coco e massa de pastel. Na elaboração do biscoito proveniente da fécula de araruta com adição de coco, ao final da preparação, observou-se um biscoito de cor clara, de consistência aerada, com certa fragilidade, sendo crocante, leve e de sabor levemente adocicado. E na elaboração do pastel de araruta, ao final da preparação, observou-se um pastel leve, crocante e que apresentou maior qualidade sensorial ao ser frito em óleo com temperatura entre 140 a $160^{\circ} \mathrm{C}$, sendo testada também sua cocção ao forno que promoveu um produto mais resistente à mordida. Portanto, com a ausência do glúten no rizoma, torna-se viável o consumo para pessoas portadoras da doença celíaca, tornando-se mais uma opção para produção de alimentos que podem ser direcionados a pessoas com restrições alimentares ou não.
\end{abstract}

Palavras-chave: Cultura; Fécula; Gastronomia; Processamento.

\begin{abstract}
The present work had as objective to characterize the botanical part of the arrowroot (Maranta arundinacea L.), by means of a bibliographical revision, and to describe the processing of the starch and of three different classifications of flours, being them: yellow, white and integral. The characteristics of the forms of reforestation of arrowroot, which carries cultural value, and its forms of consumption and applications were described. In addition, an overview was made of the centesimal composition of the arrowroot starch compared to other types of starches, showing its great potential for use in gastronomic preparations. Two preparations were emphasized: arrowroot cookie with coconut and pastry dough. In the elaboration of the cookie made from arrowroot starch with the addition of coconut, at the end of the preparation, a light colored cookie was observed, of aerated consistency, with a certain fragility, being crunchy, light and with a slightly sweet flavor. And in the preparation of the arrowroot pastry, at the end of the preparation, it was observed a light, crispy pastry that presented a better sensory quality when fried in oil with a relatively low temperature.
\end{abstract}


Therefore, with the absence of gluten in the rhizome, it becomes feasible to consume for people with celiac disease, becoming another option for the production of foods that can be directed to people with dietary restrictions or not.

Keywords: Culture; Gastronomy; Processing; Starch.

\begin{abstract}
Resumen
El presente trabajo tuvo como objetivo caracterizar la parte botánica del arrurruz (Maranta arundinacea L.), mediante una revisión bibliográfica, y describir el procesamiento del almidón y de tres diferentes clasificaciones de harinas, siendo ellas: amarilla, blanca e integral. Se describieron las características de las formas de repoblación del arrurruz, que tiene un valor cultural, y sus formas de consumo y aplicaciones. Además, se hizo un repaso de la composición centesimal del almidón de arrurruz en comparación con otros tipos de almidón, mostrando su gran potencial de uso en preparaciones gastronómicas. Se hizo hincapié en dos preparaciones: la galleta de arrurruz con coco y la masa de hojaldre. En la elaboración de la galleta a partir del almidón de arrurruz con adición de coco, al final de la preparación, se observó una galleta de color claro, de consistencia aireada, con cierta fragilidad, siendo crujiente, ligera y de sabor ligeramente dulce. Y en la elaboración de la pasta de arrurruz, al final de la preparación, se observó una pasta ligera, crujiente y que presentaba mejor calidad sensorial al ser frita en aceite con una temperatura relativamente baja, siendo también probada su cocción en el horno que promueve un producto más resistente a la mordida. Por lo tanto, con la ausencia de gluten en el rizoma, se hace factible su consumo para las personas con enfermedad celíaca, convirtiéndose en otra opción para la producción de alimentos que pueden ser dirigidos a personas con restricciones alimentarias o no.

Palabras clave: Almidón; Cultivo; Gastronomía; Procesamiento.
\end{abstract}

\title{
1. Introdução
}

A araruta (Maranta arundinacea L.) é uma planta nativa da América do Sul que apresenta grande importância cultural e gastronômica. Além de apresentar algumas propriedades e características que se destacam, como a alta digestibilidade e a ausência do glúten, ela proporciona várias opções de preparos que a utilizam como base, por exemplo, biscoitos, mingau, molhos, entre outros (Fernandes \& Nascimento, 2019). No entanto, o cultivo de forma mais intensa feito quase na sua totalidade por comunidades tradicionais e a perda de espaço na indústria devido à mandioca, marcam dificuldades a serem contornadas para que haja o resgate da araruta (Souza, 2016). Com a notória relevância do uso da araruta em setores alimentícios e não alimentícios, o trabalho objetivou resgatar o uso deste vegetal por meio da descrição, elaboração do fluxograma de beneficiamento da fécula e da farinha, bem como a aplicação da fécula de araruta em preparos gastronômicos. Ressalta-se ainda a importância gastronômica da araruta exposta por meio dos preparos exemplificados e descritos no presente trabalho.

\section{Metodologia}

Esta pesquisa se caracteriza como um estudo de caso em caráter qualitativo, exploratório e documental, sendo dividida em três etapas: 1 - Levantamento bibliográfico; 2 - Acompanhamento do beneficiamento dos produtos da araruta e entrevista semiestruturada na comunidade Vieira do Carlos/Itapipoca/Ceará; e 3 - Escolha das preparações gastronômicas e desenvolvimento de ficha técnica com a sua padronização.

O levantamento bibliográfico foi obtido a partir de uma breve pesquisa nas principais bases de dados: Science Direct, SCOPUS, Scielo.org, FAO Fisheries and Aquaculture e Wiley Online Library. Durante a busca foram utilizados os descritores “Araruta", "Maranta arundinacea", "Composição centesimal” e "Fécula da araruta".

Os dados foram coletados através de visita in locu a comunidade Vieira dos Carlos, no Assentamento Várzea do Mundaú, Município de Trairi-CE. Todo o processo realizado na localidade foi registrado por meio de fotos e vídeos. A sistematização do estudo se deu com a construção do fluxograma das etapas de beneficiamento da araruta. A entrevista semiestruturada foi conduzida durante a execução do beneficiamento com foco nas questões: Por que se faz dessa maneira? Onde aprendeu? Qual importância que a araruta tem para você e a para a sua comunidade? Que lembranças te trazem?

Para as preparações gastronômicas foram elencadas aquelas que mais se aproximavam da realidade da comunidade estudada, considerando o saber popular e cultural; e ainda aquelas que seriam viáveis para uma possível comercialização. Depois 
de escolhidas as preparações, com base na representação cultural e na popularidade, aliada à acessibilidade da comunidade e das pessoas com restrições alimentares (como os celíacos), foram elaboradas as fichas técnicas padronizadas e foram executadas as preparações sob diferentes métodos de cocção. Posteriormente, foram analisadas as características sensoriais pelo grupo que compôs esta pesquisa, considerando as impressões globais de cada produto.

\section{Resultados e Discussão}

\subsection{Histórico Botânico}

A araruta (Maranta arundinaceae L.) é uma planta herbácea, pertencente à família Marantaceae (ordem Zingiberales), nativa da América do Sul. Tornou-se conhecida e disseminada no mundo somente com a descoberta da América, tendo sua propagação mais intensa feita pelos portugueses, do mesmo jeito que aconteceu com a mandioca. A partir da África Ocidental passou por todo o restante do continente, pela Índia Oriental, pelo Sudeste Asiático e pela Austrália. Foi encontrada também em todo o Brasil, desde o Nordeste até o Sul do país (Albuquerque \& Pinheiro, 1970). Há indícios de que os indígenas eram os maiores detentores de conhecimento sobre a araruta, com o cultivo realizado há cerca de 7.000 anos (Neves, Coelho \& Almeida, 2005). Cultivado no Brasil, principalmente por familiares agricultores, esse vegetal possui grande importância na alimentação de algumas comunidades rurais (Brasil, 2013; Kinupp \& Lorenzi, 2014).

Durante a busca por nomes populares desse tubérculo foram encontrados, através do Banco de Plantas Notáveis (Porto, 2021), os seguintes nomes: araruta, agutingue-pé, araruta-caixulta, araruta comum, araruta-palmeira e embiri. Na literatura, porém, foram encontrados quatro dos seis nomes citados anteriormente, dentro de um grupo de nomes como sendo "variedades": araruta-bastarda, araruta-caixulta, araruta-comum, araruta-da-flórida, araruta-de-porco, araruta-do-campo, araruta-do-méxico, araruta-especial, araruta-gigante, araruta-palmeira, araruta-raiz-redonda (ovo de pata), araruta-ramosa, agutingue-pé e embiri (Barufaldi, 2013). A Maranta arundinacea foi mencionada também como araruta, maranta, arrowroot ou west indian arrowroot (Kinupp \& Lorenzi, 2014). Afirma-se, contudo, que os colonizadores ingleses chamavam os produtos de "Aruak root starch", isto é, "polvilho da raiz dos Aruak", que acabou corrompido para "arrowroot", que é derivado para o português como araruta (Neves et al., 2005).

Esta planta desenvolve-se formando touceiras, podendo atingir 1,2 m de altura. Possui caules curvos que crescem horizontalmente sob o solo e que emitem raízes, folhas pecioladas e com longas bainhas foliáceas; flores pequenas e na cor branca, que nascem solitárias, mas podem aparecer em forma de panículas, ou seja, em agrupamento de três ou quatro. Seus frutos são de tamanho pequeno e de formato plano-convexo, com sementes rugosas de cor vermelho-pálida e com arilo amarelo (Corrêa, 1984).

No Brasil, há três variedades de importância na cultivação: Comum, Creoula e Banana. Entre estas, as duas primeiras prevalecem, sendo mais explorada a primeira. As ararutas do tipo 'comum', com cerca de $60 \mathrm{~cm}$ de altura, produzem féculas com excelente qualidade, apresentam rizomas claros (cônico-alongados ou em formato de fuso), cobertos por escamas e que podem atingir até $30 \mathrm{~cm}$ de comprimento. A qualidade do solo, porém, pode interferir no desenvolvimento, embora normalmente o tamanho esteja entre 10 a $25 \mathrm{~cm}$. As ararutas do tipo 'creoula', que são de grande porte (superior a 1,0 m), apresentam rizomas na superfície do solo em forma de touceiras, os quais necessitam passar por várias lavagens para perder a camada escura da superfície, caso contrário, produzem fécula de coloração escura e com baixa qualidade. Nas condições tropicais, possuem florescimento fertil, sem formação de frutos e sementes (Leonel \& Cereda, 2002; Monteiro \& Peressin, 2002).

O tempo da colheita acontece normalmente entre 10 e 12 meses após o plantio, e duas características funcionam como indicativo de que está no tempo certo de colher: a mudança de cor das plantas, que ficam amareladas ou esbranquiçadas; e a aparência murcha das folhas. O desenvolvimento da Maranta arundinaceae L. acontece melhor em regiões de clima úmido e 
quente, entretanto, pode ser plantada em uma ampla faixa de condições ambientais, como em solos arenosos e profundos, ricos em matéria orgânica que favorecem o desenvolvimento dos rizomas. Devem ser evitados, porém, os solos pesados e muito argilosos, pois não toleram muita umidade; ou solos arenosos, muito secos e pobres. Os solos de baixada, desde que bem drenados, são adequados (Silva \& Monteiro, 1968). Por serem cultivadas por meio de rizomas e tubérculos, essas espécies podem naturalmente sumirem, sendo necessário que haja um constante replantio para a sua propagação (Neves et al., 2005).

\subsection{Formas de Consumo e Aplicação}

Determinadas espécies que pertencem a essa família são empregadas em ornamentação de ambientes, enquanto outras são exploradas pela indústria de fécula voltadas ou não ao consumo humano (Costa, Espinelli \& Figueiredo, 2008). Segundo Nogueira, Fakhouri e Oliveira (2018), a fécula pode ser aplicada na indústria de alimentos como agente espessante, gelificante, e como substituto de gordura em alimentos, podendo ser citados como exemplos os molhos e condimentos. Além do setor alimentício, ela é usada na formulação de cosméticos, de aerossóis e de pó para a pele; na produção de embalagens biodegradáveis de alimentos e como agente de encapsulamento em produtos farmacêuticos. Os caules rizomatosos das ararutas são consumidos normalmente no processo de extração de fécula, objetivando a fabricação de pães e biscoitos. A fécula possui uma excelente digestibilidade, sendo bastante apreciada (Brasil, 2013). Os biscoitos elaborados com essa fécula derretem na boca, além de apresentarem suavidade e leveza, características que, aliadas à facilidade de digestão, tornam o mingau de araruta recomendado para crianças e idosos (Coelho, Santos, Almeida, Silva \& Neves, 2005). Além disso, foram encontradas na literatura outras formulações com a elaboração da fécula de araruta, como bolo, pudim, recheio de tortas e como agente espessante (Kay, 1973).

O sumo da araruta era utilizado contra picada de insetos, enquanto a fécula era usada contra a diarreia por algumas tribos indígenas brasileiras. Já a fibra da araruta tem sido empregada para dar qualidade especial ao papel (Coelho et al., 2005). Essa fibra já foi bastante aproveitada para alimentar os animais, mas a sua valorização na alimentação humana implica maior busca da indústria por outros usos alternativos, de modo que a farinha contenha tanto a fibra como a fécula (Neves et al., 2005). Ademais, algumas outras utilizações foram identificadas na literatura como a aplicação local do rizoma fresco feita por indígenas em casos de ferimentos provocados por flechas, envenenadas ou não, por conterem substâncias acres, e como antídoto nas mordidas de cobras peçonhentas (Monteiro \& Peressin, 2002).

\subsection{Características de Formas de Reflorestação da Araruta}

O povo Tremembé da Barra do Mundaú, em Itapipoca (CE) realiza a Festa do Murici e do Batiputá de 8 a 12 de janeiro e na ocasião são distribuídas mudas de araruta como forma de incentivar a questão do reflorestamento, as quais são plantadas dentro do espaço festeiro, a fim de que impulsione a medicina tradicional na comunidade e o compromisso com a mãe terra, com troca de experiências entre guardiões da sabedoria, líderes e jovens na aldeia. Além disso, o intuito do plantio é: quem plan tar a muda, estará plantando uma vida e deverá voltar no ano seguinte na confraternização para ver a como está a planta e, assim, a propagação é estimulada (Cetra, 2013).

Foi relatado por Estevão (2019) que existem diferentes modos de plantio. Ele relata ainda que a araruta é uma planta a qual gosta de sombra com terra úmida, podendo ser cultivada em meio a plantios de milho, batata, mandioca, cajueiro e mata sem distinção, dessa forma, contribuindo com uma ótima propagação, maior rendimento e com excelente qualidade.

\subsection{Beneficiamento da Fécula da Araruta (Maranta arundinacea L.)}

Todo o beneficiamento e a construção do fluxograma de produção foram provenientes de acompanhamento in loco de uma extração na comunidade Vieira dos Carlos-Assentamento Barra do Mundaú-Trairi, desde a colheita até os produtos descritos 
neste trabalho. As técnicas de beneficiamento aplicadas são as mesmas utilizadas para a cultura da mandioca. Entretanto, adaptando-se algumas etapas às especificidades da araruta. Segue o fluxograma abaixo.

Fluxograma 1 - Beneficiamento de fécula da araruta.

SELEÇÃO DOS RIZOMAS PARA BENEFICIAMENTO

$\downarrow$

2. LAVAGEM E DESCASCAMENTO

$\downarrow$

3. TRITURAÇÃO

$\downarrow$

4. FILTRAÇÃO $\rightarrow$ BIOMASSA

$\downarrow$

5. DECANTAÇÃO E LAVAGEM

$\downarrow$

6. SECAGEM

Fonte: Autores (2021).

\subsubsection{Seleção entre os rizomas para beneficiamento e para plantio}

Baseado no acompanhamento do plantio e nos demais processos, a colheita acontece preferencialmente 8 meses após o plantio, caso contrário, afetará de forma negativa toda a cadeia de produção, pois interfere diretamente no rendimento devido à demora para a colheita do rizoma favorecer o desenvolvimento de uma textura mais fibrosa.

Antes de realizar o processo de lavagem e descascamento, identifica-se quais rizomas serão utilizados para o beneficiamento e quais serão destinados para plantio. É desejável que no beneficiamento seja considerado qualidade e rendimento.

Os rizomas grandes, com maior conteúdo de fécula, em outras palavras, com espessura grossa, proporcionam excelente qualidade, sendo destinados para o beneficiamento de fécula, pois possuem melhor rendimento tanto na extração de fécula quanto na obtenção dos tipos de farinhas. Estes rizomas apresentam também como particularidade a cor azul nas pontas, sendo indicativo de tempo correto para colheita, consequentemente para a utilização no beneficiamento.

Pode-se observar na figura 1 a variedade entre os tipos de rizomas com diferentes finalidades. Aqueles que apresentam rizomas com pontas finas são destinados para mudas, pois não terão conteúdo significativo para a extração de fécula, por possuírem baixa qualidade e rendimento inferior, interferindo também no beneficiamento da farinha.

Escolhem-se rizomas de talos secos e com ramificação, dividindo-os em mais quantidades para um plantio de maior área. Enquanto isso, para cultivos de menor área, até mesmo um plantio caseiro, planta-se de forma direta, não havendo necessidade de divisão dos talos. Esses terão maiores ramificações, melhor desenvolvimento e maior rendimento da matéria prima. 
Figura 1 - Diferentes tipos de Rizomas e suas finalidades.

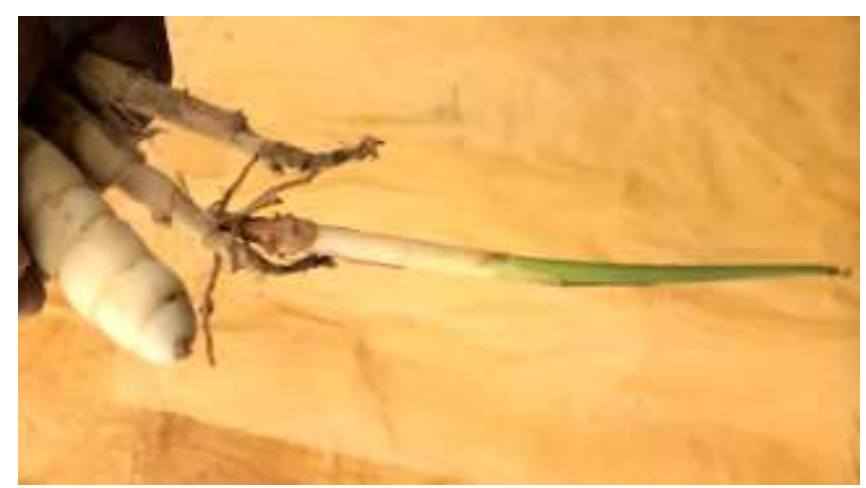

Fonte: Autores (2021).

\subsubsection{Lavagem e descascamento}

Os rizomas são colocados em imersão com água limpa em um tanque revestido de cerâmica na parte interna, tanto para que as impurezas sejam removidas como para facilitar a remoção das cascas do rizoma da araruta, que tem como característica cascas finas. Nesse processo de descascamento, é necessário que sejam esfregados com as mãos e lavados no mesmo momento, separando-as (Figura 2). Ainda assim, é possível também que as cascas sejam removidas sem a utilização da água, de forma seca, sendo um processo mais demorado, mas de fácil execução.

Figura 2 - Araruta em imersão na água para descascamento.

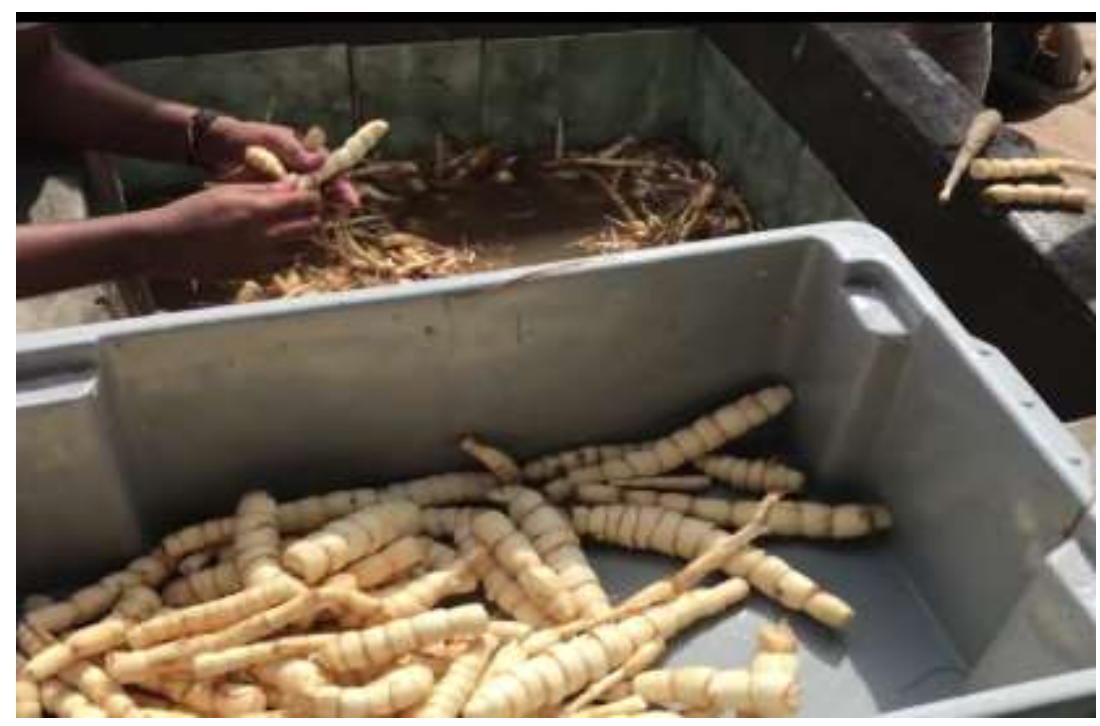

Fonte: Autores (2021).

\subsubsection{Trituração}

Utiliza-se um triturador com base de madeira, contendo uma lâmina que facilita a moagem, usando o próprio tanque de lavagem como suporte para que o triturador seja fixado e facilite o manuseio no momento da trituração. Todo o trabalho é feito de forma manual, em que a matéria prima é empurrada com auxílio de um bastão ao encontro da lâmina (Figura 3). Dessa forma, o material já triturado cai sobre num recipiente que está abaixo do moedor. 
Figura 3 - Araruta no processo de trituração.

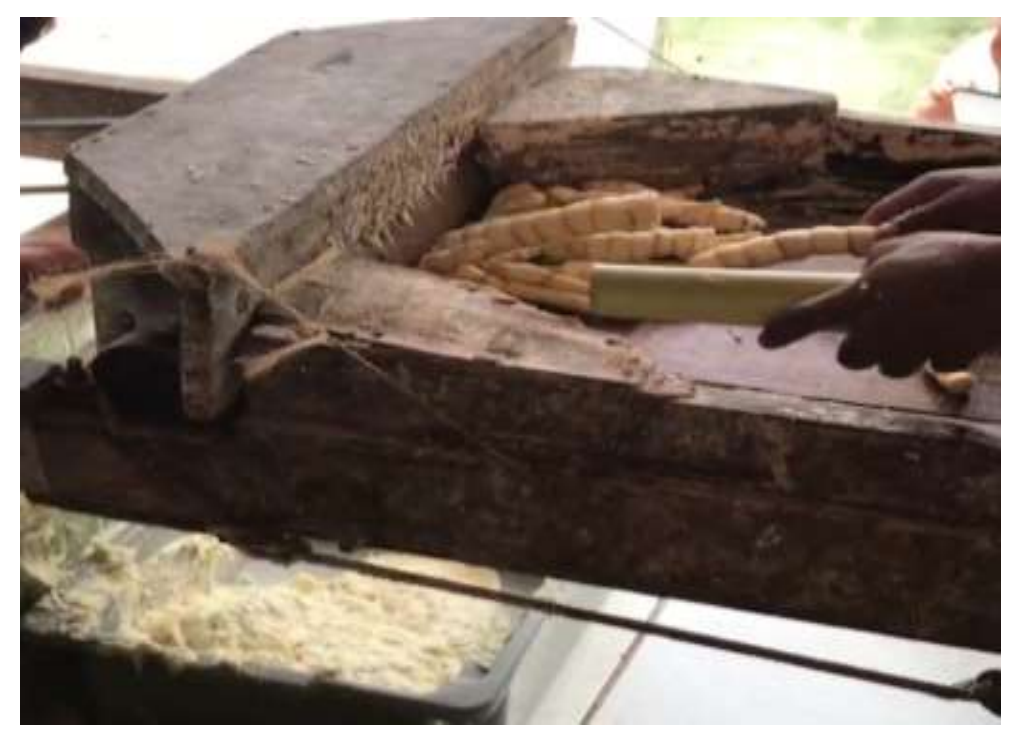

Fonte: Autores (2021).

\subsubsection{Filtração}

O material tem como característica uma massa grossa, fibrosa, de cor um pouco escura, sendo necessário homogeneizar a massa com adição de água em um recipiente limpo. Em seguida, a massa é comprimida em um tecido de nylon fixado nas 4 pontas em estacas de madeiras de forma plana (Figura 4). No momento em que a massa é espremida, recomenda-se que haja movimentos de compressão e espalhamento, adicionando água potável para facilitar a separação de fluido contendo amido e, consequentemente, menor perda da fécula retida entre o material fibroso que possivelmente ficará retido no nylon. Entretanto, aconselha-se que não haja exageros na adição de água nesse processo, pois esperam-se resíduos de fécula entre esse conteúdo fibroso, chamado de biomassa, para que seja possível o beneficiamento da farinha, descrito posteriormente. $\mathrm{O}$ fluido, que varia de cor ao decorrer das lavagens, é coletado em recipientes que ficam abaixo do nylon.

A biomassa é definida como uma matéria orgânica proveniente de origem vegetal constituída por diferentes tipos de células da qual a estrutura e composição podem variar as partes ou espécies de plantas. Entretanto, as paredes das células da biomassa são formadas por microfibrilas de celulose envolvidas por uma matriz de hemicelulose e lignina (Shafizadeh, 1982; Mesa, 2011). Não foi encontrado o uso da biomassa da araruta na geração de energia, sendo necessário mais estudos para avaliação de outros usos a fim de um aproveitamento integral e sustentável desse processo. 
Figura 4 - (A) Tela de nylon para o processo de filtragem e lavagem e (B) Processo de comprimir e espalhar massa.

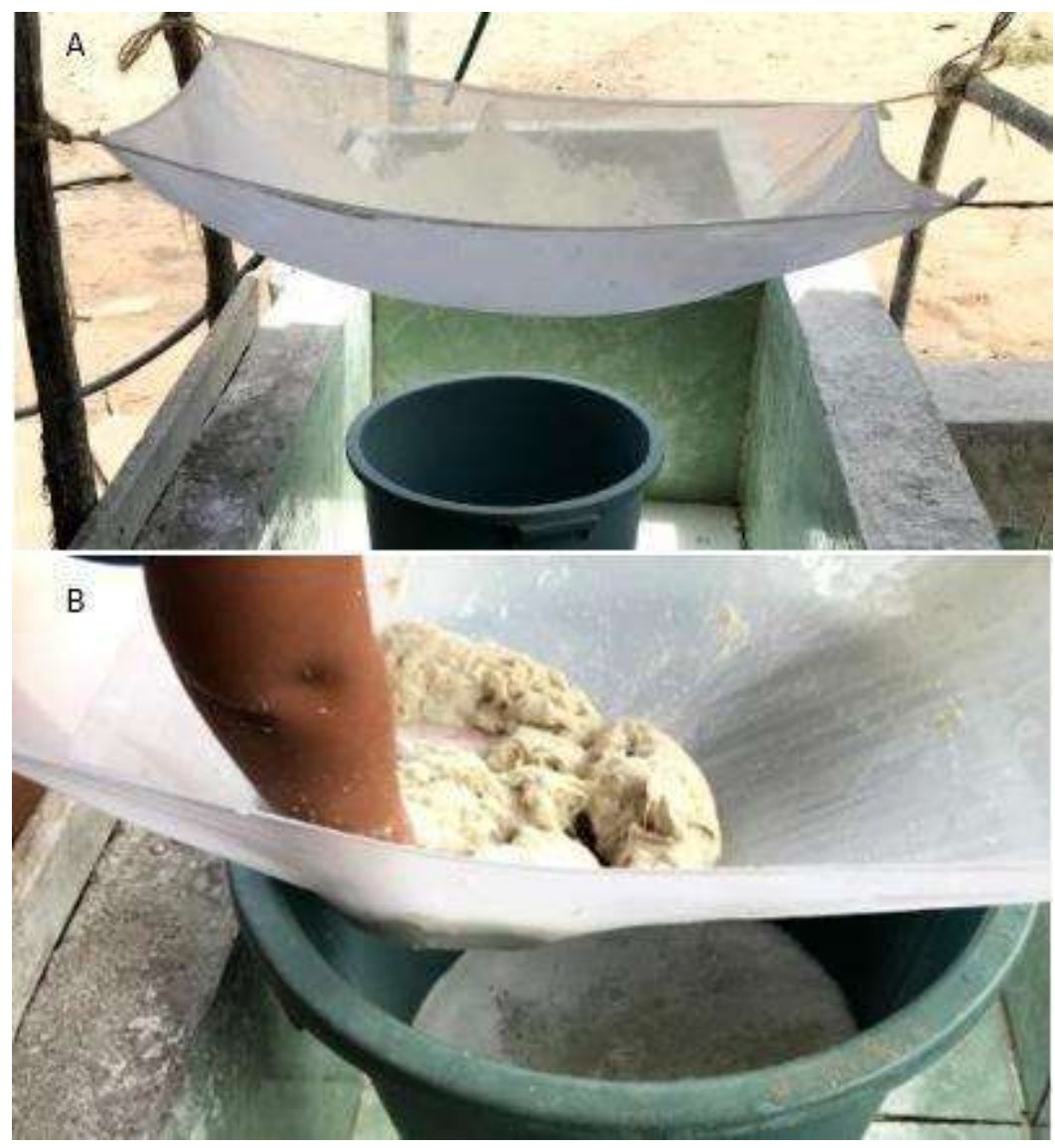

Fonte: Autores (2021).

\subsubsection{Decantação e lavagem}

No processo de decantação, é necessário que ocorram, no mínimo, 3 lavagens até o beneficiamento final. A primeira decantação dura, no máximo, 1 hora, passando novamente o conteúdo por filtragem com o objetivo de garantir maior rendimento da fécula final, sendo suficiente no mínimo 30 minutos para os demais processos de decantação, mantendo o recipiente coberto para não ocorrer contaminação física.

Na primeira decantação, não há necessidade de adição de água, pois já foi adicionada água na araruta moída, podendo ser proveniente também do processamento anterior na primeira filtração. Poderá haver formação de bolhas na parte superior do líquido. Após o tempo de espera, retira-se a água turva cuidadosamente para que ambos (água e fécula) não se misturem novamente, restando a fécula úmida no fundo do recipiente. Antes da segunda decantação acontecer, adiciona-se água tratada em média 3 vezes a mais do conteúdo resultante com o intuito de homogeneizar e para uma eficiência no procedimento de lavagem (Figura 5). Logo em seguida, descarta-se a água e repete-se a etapa anterior para uma terceira decantação. Ao finalizar a última etapa, obtém-se um amido. 
Figura 5 - (A) Formação de bolha na primeira decantação, (B) Fécula na primeira decantação e (C) Fécula final.

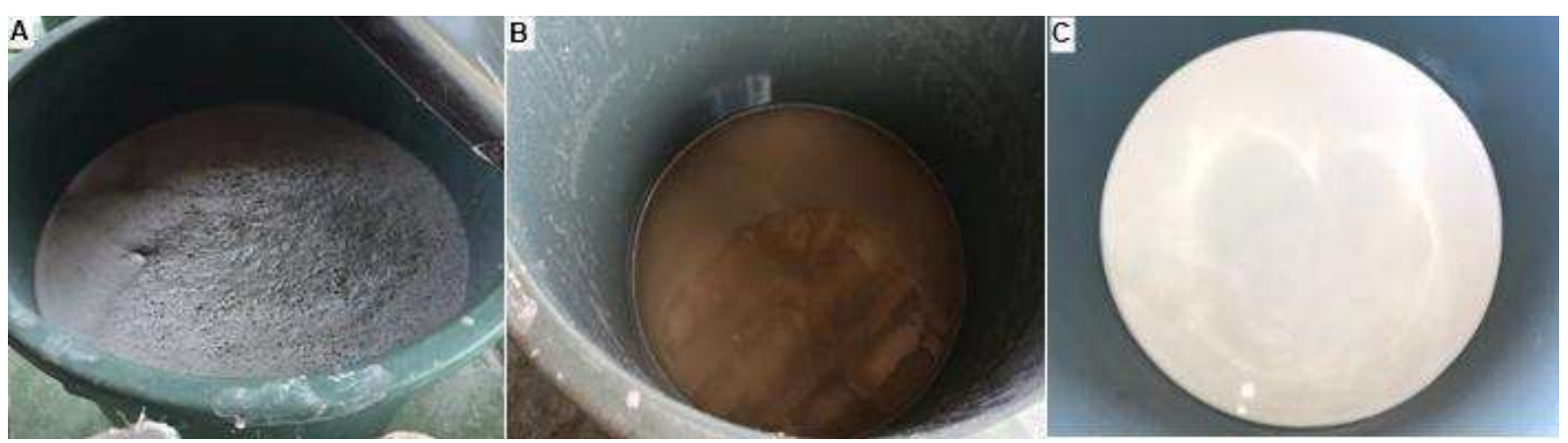

Fonte: Autores (2021).

\title{
3.4.6 Secagem
}

Posteriormente, a fécula estará pronta para a secagem, sendo possível secar de duas formas: por meio da secagem natural ao sol ou com a utilização de secagem forçada utilizando um forno, a qual é aquecida com a incineração de lenha. No entanto, ambos os processos de secagem possuem vantagens e desvantagens, podendo ser citados alguns exemplos para cada.

No processo de secagem natural, suas vantagens são: maior facilidade no manuseio da matéria prima e ausência de custos, enquanto as desvantagens são: demora no processo, a impossibilidade de controlar as condições ambientais (umidade, sol, chuva e vento) e sanitárias (roedores, insetos e poeiras). Já no processo de secagem forçada utilizando o aquecimento da placa, aumenta-se a rapidez no processo, ou seja, sendo otimizada a operação e alta capacidade na secagem, com desvantagens no superaquecimento da matéria prima, em outras palavras, promovendo uma possível gelificação parcial com possibilidade de perda parcial ou total desta propriedade a depender do tempo e temperatura empregados. De modo geral, os dois métodos de secagem exigem cuidados.

\subsection{Beneficiamento de Três Tipos de Farinhas a Partir da Biomassa da Araruta}

Nesse beneficiamento, para os diferentes tipos de produtos, usa-se como base a biomassa proveniente do beneficiamento da fécula, descrito no ponto 3.4.4. Dessa forma, resultando em três tipos de farinhas.

\subsubsection{Farinha amarela}

Fluxograma 2 - Beneficiamento da farinha amarela proveniente da biomassa da araruta.

\author{
PRENSAGEM \\ $\downarrow$ \\ SECAGEM NATURAL ENTRE 2 A 3 DIAS \\ $\downarrow$ \\ PENEIRAMENTO
}

Fonte: Autores (2021).

A farinha amarela é obtida depois que a biomassa é submetida à prensagem e à secagem de forma natural, entre 2 e 3 dias ao sol. Dessa forma, intensifica-se a cor ao passar dos dias, tornando-se um produto mais interessante, atrativo e procurado 
pelos consumidores. Além disso, é possível aumentar a vida útil deste produto, se desejar, entre 10 e 15 dias do beneficiamento, podendo usar a aplicação de "torragem" de forma rápida. O peneiramento pode ocorrer em peneiras com malhas de granulometria grossa, caso o desejado seja uma farinha com fibras maiores, como também podendo ser com granulometrias pequenas, se o objetivo é de uma farinha fina e com conteúdo "fibroso" mais fragmentado. Indica-se que todos os tipos de farinha sejam armazenados em local seco e arejado.

\subsubsection{Farinha branca}

Fluxograma 3 - Beneficiamento da farinha branca proveniente da araruta.

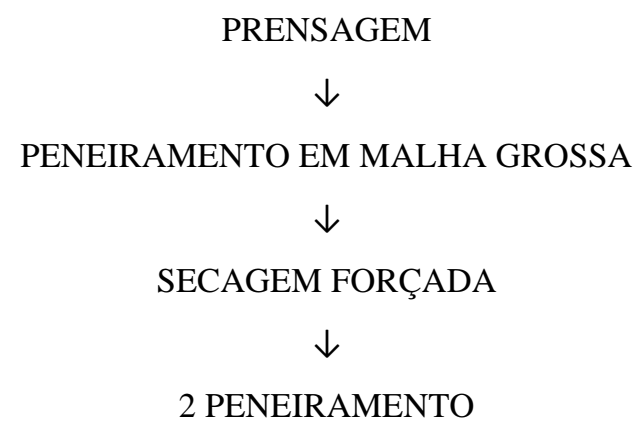

Fonte: Autores (2021).

A partir da biomassa é possível a obtenção da farinha branca. Na farinha branca, além dos processos de prensagem, peneiramento, ela será seca, isto é, a farinha será submetida à "secagem" com a utilização de equipamento popularmente conhecido como tacho, aquecido por 5 minutos no máximo, sendo adicionado sobre a superfície pouca quantidade para que a secagem aconteça de forma homogênea sempre em movimentação do conteúdo a ser seco, para maior eficiência e adequação do produto final. Em seguida, é desejável que haja dois peneiramentos com malhas que promovam uma farinha com granulometria homogênea e pequena e com o objetivo de adquirir uma farinha fina.

\subsubsection{Farinha integral}

Para o beneficiamento da farinha integral é utilizado todo o conteúdo existente no rizoma, isto é, não passa por extração da fécula, farinha que terá um maior rendimento e um maior conteúdo de amido. 
Fluxograma 4 - Beneficiamento da farinha integral proveniente da araruta.

SELEÇÃO DOS RIZOMAS PARA BENEFICIAMENTO

$\downarrow$

LAVAGEM E DESCASCAMENTO

$\downarrow$

TRITURAÇÃO

$\downarrow$

PRENSAGEM

$\downarrow$

PENEIRAMENTO EM MALHA COM MALHA GROSSA

$\downarrow$

SECAGEM NATURAL À SOMBRA

Fonte: Autores (2021).

A partir da trituração de todo o rizoma, segue direto para a prensagem, sem passar por nenhuma lavagem, o que mantém o conteúdo integral, após essa prensagem é peneirada em peneira rústica, com estrutura de madeira, com malha grossa em aço garantindo resistência durante o manuseio. Dessa forma, permite-se a passagem de toda a biomassa reduzindo o tamanho dos componentes fibrosos. Contudo, a secagem natural ocorre na sombra em ambiente arejado e dura em média 72 horas, com movimentação da farinha para que a secagem aconteça de forma homogênea. Quando estiver seca, ela é peneirada e armazenada. Por essa farinha conter seu conteúdo quase integralmente quando se remete ao rizoma, se torna um tipo de farinha bastante atrativo ao consumidor.

\subsubsection{Funções dos equipamentos utilizados no beneficiamento dos diferentes tipos de farinhas}

Foram utilizados três equipamentos (prensa, peneira e forno), no processo de beneficiamento dos tipos de farinhas e da fécula. De modo geral, ambos com as mesmas finalidades em otimização de cada operação.

A prensa usada tem estrutura de madeira, de médio porte e tem como objetivo a remoção de água presente na biomassa, o que auxilia na técnica de secagem das farinhas.

Já a aplicação da peneira com estrutura de madeira, com malha grossa, de aço é resistente durante o impacto do manuseio e tem como função reter na superfície do utensílio a parte "fibrosa" durante o peneiramento da biomassa, de modo que haja a separação dos dois conteúdos. Entretanto, no primeiro peneiramento com a malha descrita anteriormente, é aceitável que passem partes da fibra da araruta, consequentemente resultando numa farinha com granulometria grossa. Podendo utilizar outros tipos de malhas utilizando uma malha pequena, assim resultará uma farinha de granulometria fina.

A metodologia de secagem pode acontecer de três modos: secagem natural ao sol, secagem natural à sombra e secagem forçada, utilizando um equipamento aquecido com lenhas incineradas. Esse método de secagem consiste na otimização do processo, consequentemente na remoção de toda a água presente na farinha, deixando-a seca e pronta para consumo.

\subsection{Composição Centesimal da Araruta}

A Tabela 1 apresenta dados da composição centesimal da fécula da araruta por diferentes autores. 
Tabela 1 - Composição Centesimal da fécula da Araruta.

\begin{tabular}{|c|c|c|c|c|}
\hline Parâmetros & $\begin{array}{l}\text { Souza et al. } \\
\qquad(2020)\end{array}$ & $\begin{array}{c}\text { Melo } \\
(2019)\end{array}$ & $\begin{array}{l}\text { Rodrigues } \\
\text { (2014) }\end{array}$ & $\begin{array}{c}\text { Ferrari e Leonel } \\
\qquad(2005)\end{array}$ \\
\hline $\begin{array}{c}\text { Umidade } \\
(\%)\end{array}$ & 04,28 & 12,06 & 10,90 & 83,29 \\
\hline $\begin{array}{l}\text { Carboidratos } \\
\qquad(\mathrm{g} / 100 \mathrm{~g})\end{array}$ & - & - & 88,46 & - \\
\hline $\begin{array}{l}\text { Proteínas } \\
(\mathrm{g} / 100 \mathrm{~g})\end{array}$ & 00,09 & 00,09 & 00,41 & 00,85 \\
\hline $\begin{array}{c}\text { Lipídeos } \\
(\mathrm{g} / 100 \mathrm{~g})\end{array}$ & - & 00,11 & - & - \\
\hline$\underset{(\mathrm{g} / 100 \mathrm{~g})}{\mathbf{p H}}$ & - & 07,05 & 07,30 & - \\
\hline $\begin{array}{c}\text { Fibra } \\
(\mathrm{g} / 100 \mathrm{~g})\end{array}$ & 00,36 & 00,44 & - & 01,40 \\
\hline $\begin{array}{c}\text { Cinzas } \\
(\mathrm{g} / 100 \mathrm{~g})\end{array}$ & 00,27 & 00,15 & 00,22 & 00,45 \\
\hline
\end{tabular}

Fonte: Autores (2021).

Os dados de cada parâmetro mostrados na Tabela 1 mostraram variações nos resultados, supostamente por consequências do tipo de clima, tamanhos diferentes, diferentes épocas da realização da colheita, variedades e formatos (Chitarra \& Chitarra, 2005).

No parâmetro de umidade houve diferenças entre os valores. No estudo de Souza et al. (2020), o valor expresso na tabela 1 foi de 4,28\% referente aos 336 dias após o plantio da araruta. Contudo, o autor realizou 5 análises da composição centesimal em diferentes dias após o plantio (253, 273, 295, 314 e 336). Dessa forma, o menor valor para umidade foi com 295 dias após o plantio. Já na pesquisa de Rodrigues (2014), foram encontrados dados para diferentes variedades da araruta (Comum e Ovo de Pata), o autor não relata quantos dias foi feita a colheita após o plantio. O dado expresso neste trabalho é da araruta comum, sendo similar ao dado da variedade ovo de pata com 10,2 \%. Esses valores foram próximos da composição química da fécula da araruta e da mandioca identificado por Melo (2019). Ferrari e Sarmento (2005) encontraram dados diferentes para a composição centesimal em diferentes meses (10, 12 e 14), 83,29 \%, 71,91 \% e 69,92\%, respectivamente, em umidade. Contudo, não foi relatada a variedade da araruta.

O valor de carboidrato identificado por Rodrigues (2014) com 88,46\% para a variedade comum, é similar à variedade de ovo de pata $89,38 \%$, sendo próximo ao valor 90,29\% de carboidratos das raízes da batata doce e inferiores ao valor $97,97 \%$ da fécula da batata doce (Leonel, Jaquey \& Cereda, 1998).

No parâmetro proteínas, os valores de Souza et al. (2020) e Melo (2019) foram iguais a 0,09\%, porém este valor foi inferior ao encontrado por Rodrigues (2014) para as variedades comum e ovo de pata, respectivamente, $0,41 \%$ e $0,27 \%$, que também foram valores inferiores ao encontrado na literatura de Ferrari e Leonel (2005), com 0,85\%, todavia, na mesma literatura para proteínas com o rizoma de 12 meses $1,7 \%$ e com 14 meses $1,91 \%$.

Melo (2019) encontrou valores próximos para lipídeos nas féculas de mandioca, batata doce e araruta, respectivamente, $0,09 \%, 0,12 \%$ e $0,11 \%$. 
O pH identificado nas variedades comum 7,30 e ovo de pata 6,80, tiveram valores próximos aos encontrados por Rodrigues (2014). Além disso, Melo (2019) identificou valores com similares 6,28, 6,54 e 7,05 nos amidos, respectivamente, mandioca, batata doce e araruta. Sendo semelhantes ao encontrado nos estudos de Leonel et al. (1998) para fécula da batata doce com valor de 6,37 .

A quantidade de fibra exposta na tabela 1 distinguiu-se entre eles. Entretanto, os valores identificados por Melo (2019) em batata doce $0,35 \%$, mandioca $0,61 \%$ e araruta $0,44 \%$ foram inferiores ao encontrado por Ferrari e Leonel (2005) com $1,40 \%$, valor este superior ao encontrado em batata doce por Leonel et al. (1998).

No parâmetro cinzas, os valores foram próximos entre os autores, podendo ser comparado com a quantidade de cinzas no amido de batata doce $0,01 \%$ e $0,12 \%$ para mandioca descritos por Melo (2019) e 0,50\% para fécula da batata doce analisado por Leonel et al. (1998).

De modo geral, durante a discussão dos valores, foi observado que os resultados dos parâmetros apresentaram alterações ocasionadas possivelmente por diversos fatores como variedade da araruta, tempo de colheita, diferentes tipos de solo realizado o cultivo, temperatura do ambiente, clima e formas de cultivo. Compreende-se que, por ser uma planta cultivada em pequena escala e por grupos específicos, seria necessário um mapeamento das áreas cultivadas, assim como sua análise química e físicoquímica para ressaltar seus parâmetros nutricionais e sua usabilidade em preparações gastronômicas.

\subsection{Uso da Fécula da Araruta em Preparações Gastronômicas}

A fécula pode ser aplicada na indústria de alimentos como agente espessante, gelificante, substituto de gordura em alimentos podendo ser citados como exemplos os molhos e condimentos (Nogueira et al., 2018). Essa capacidade deve-se à gelatinização da fécula, que acontece quando ocorre a quebra das ligações de hidrogênio no amido, fazendo com que os grânulos se quebrem e se dissociem formando um gel. Desta forma, a propriedade de gelatinização é controlada, em parte, pela estrutura da amilopectina e a composição do amido. A fécula gelatinizada confere corpo, textura e estabilidade. Entretanto, a fécula tem limitações ao ser usada na sua forma nativa na indústria, pois é bastante sensível aos baixos pHs, às altas temperaturas e ao tratamento mecânico, o que torna necessária a sua modificação (Tester \& Morrison, 1990; Tester, 1997; Thomas; Atwell, 1999; Singh, Singh, Kaur, Sodhi \& Gill, 2003).

Os caules rizomatosos das ararutas são consumidos normalmente no processo de extração de fécula, objetivando a fabricação de pães e biscoitos. A fécula possui uma excelente digestibilidade, o que colabora para que ela seja bastante apreciada (Brasil, 2013). Os biscoitos elaborados com essa fécula derretem na boca, além de apresentarem suavidade e leveza. Essas características, aliadas à facilidade de digestão, tornam o mingau de araruta recomendado para crianças e idosos (Coelho et al., 2005).

A notória presença do biscoito de araruta nas referências utilizadas e no relato da comunidade acompanhada durante o beneficiamento implicou a escolha deste preparo como um representante que mostra a importância cultural da araruta, visto que os textos o destacam como uma preparação feita desde o início da utilização da araruta.

Assim, houve a produção do biscoito de araruta com coco, que iniciou-se utilizando-se o método cremoso (Manohar, Rao, Manohar \& Rao, 1999) entre açúcar e manteiga, depois foi acrescentado o ovo. Em seguida, depois de peneirada, a fécula de araruta foi adicionada juntamente com o coco ralado. Depois, misturou-se a massa até que fosse atingida uma textura homogênea para que pudesse ser modelada da forma desejada. Por último, foi colocada em forma untada com manteiga e levada ao forno, pré-aquecido a $180^{\circ} \mathrm{C}$. A massa possui textura seca, o que dificultou a modelagem. Ao ser concluído o preparo, obtevese um biscoito de cor clara, de consistência aerada, de maior fragilidade se comparada ao biscoito produzido com farinha de trigo, mas sendo crocante e leve, principalmente devido à baixa quantidade de gordura adicionada a preparação, e de sabor 
levemente adocicado.

Figura 6. (A) Biscoito de araruta com coco, (B) Pastel de carne com massa à base de araruta.

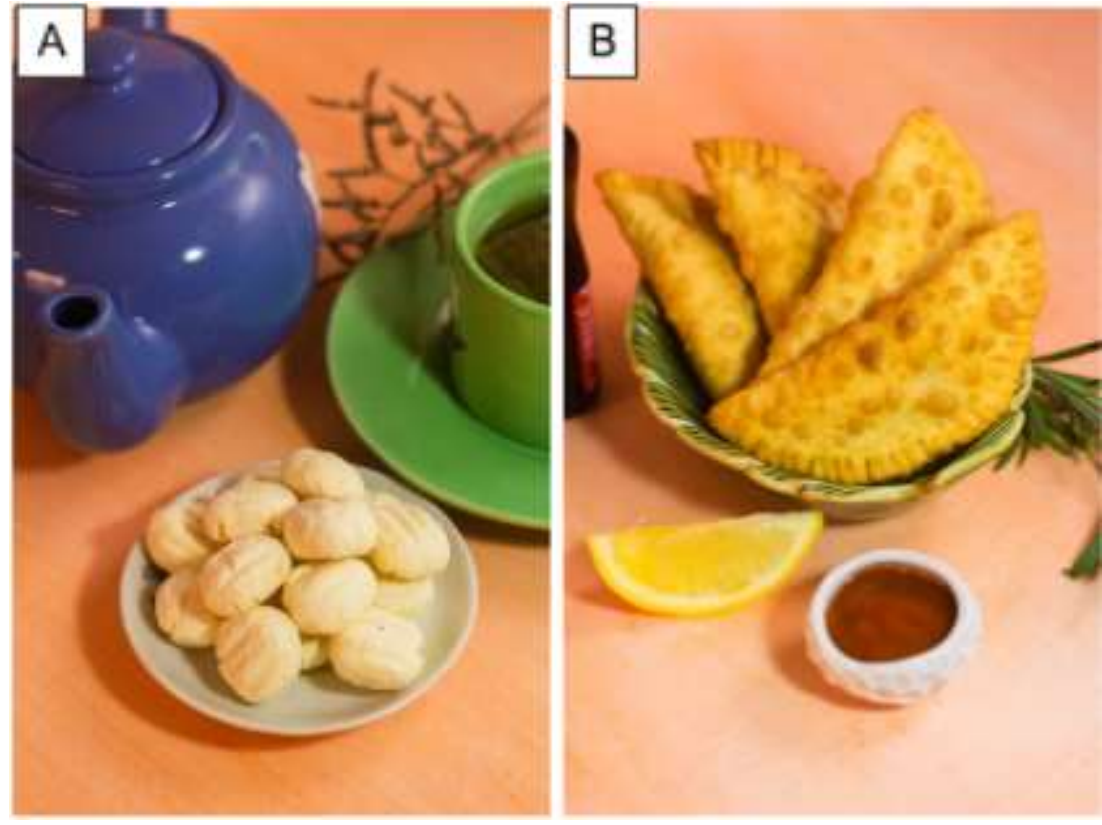

Fonte: Autores (2021).

Além disso, as indústrias alimentícias observaram que, devido à ausência de glúten, a fécula de araruta tem um grande potencial na produção de alimentos voltados aos portadores da doença celíaca, que são indivíduos intolerantes ao glúten devido a uma predisposição genética (Castro, 2018). Este fato motivou a escolha do pastel de araruta como uma preparação a ser destacada, visto que houve a união do pastel ser um alimento bastante consumido e apreciado e da possibilidade do seu consumo por aqueles que possuem restrição alimentar devido ao glúten e que a fécula de araruta se comportou adequadamente a este produto.

Com isso, para a elaboração do pastel de araruta, foram misturados a farinha de arroz, a fécula de araruta em proporções iguais e o sal em um recipiente. Em seguida, em outro recipiente, colocou-se o ovo para que a gema e clara fossem misturadas e, posteriormente, adicionou-se a cachaça. Feito isso, colocou-se a primeira mistura na bancada com um orifício no meio para que fosse adicionada a mistura líquida, incorporando do centro para fora. A adição da água foi feita aos poucos até que fosse obtida uma massa moldável. A abertura da massa foi feita entre filme plástico, com a finalidade de reduzir a adição de farinha para abrir a massa. Os pastéis foram moldados em formato de meia lua e de quadrado com tamanho aproximado de $12 \mathrm{cmx} 12 \mathrm{~cm}$ e espessura em torno de $2 \mathrm{~mm}$. Como recheio, foram utilizados queijo coalho e carne moída refogada, pois apresentam característica seca, o que não prejudica a estrutura do pastel, o qual possui baixa elasticidade devido à ausência do glúten. Por último, com o auxílio de um garfo, a massa foi fechada. Ao ser terminado o preparo, obteve-se um pastel leve e crocante, mas com espessura da massa um pouco maior que o feito com farinha de trigo. Manifestou maior qualidade sensorial ao ser frito em óleo em temperatura entre 140 a $160^{\circ} \mathrm{C}$, se comparado àquele feito sob cocção a seco, como em fritadeira elétrica à ar. Observouse que ao ser frito em uma temperatura mais elevada o pastel dourava rapidamente e não finalizava a cocção da massa que se apresenta com maior espessura que uma feita com trigo.

Dessa forma, os aspectos sensoriais obtidos ao final dos preparos citados mostram a importância do uso da araruta na panificação e na confeitaria, visto que, se comparada às alternativas de farinhas, ela possibilitou sabor e aspecto mais agradáveis. 
Além disso, a ausência do glúten na araruta permite o acesso de pessoas portadoras da doença celíaca a uma maior variedade de alimentos, que também carregam valor cultural, como o biscoito e o mingau. Outro ponto a ser enfatizado é que não existe transgenicidade na araruta como ocorre com frequência no milho (Silva, 2021).

A fécula de araruta tem um grande potencial de uso em produtos de panificação e confeitaria atingindo um público específico, como os celíacos. Suas preparações têm sabor e aparência agradáveis, que, combinado com sua alta digestibilidade e propriedades nutricionais, as tornam ainda mais atrativas. Além disso, seu uso pode promover uma fonte de renda para agricultores e garantir a existência desse tubérculo.

\section{Conclusão}

Diante do exposto, foi possível realizar um levantamento bibliográfico com o rizoma araruta (Maranta arundinaceae L.) a qual apresentou-se com grande potencial para ser explorado industrialmente. Então, a partir das técnicas utilizadas no beneficiamento da cultura da mandioca, foi possível a obtenção da fécula da araruta. A partir da biomassa que é resultante do beneficiamento anteriormente citado, obteve-se duas diferentes classificações de farinhas, além da farinha integral. E com isso resgatar o seu uso e mostrar novas possibilidades de incorporação na alimentação através de preparações gastronômicas, especificamente, biscoito de araruta com coco e massa de pastel. O cultivo da araruta deve ser fomentado para que haja maior aproveitamento dela no setor alimentício, visto que é comprovada a viabilidade de preparos que utilizam sua fécula com resultados satisfatórios, além de promover acesso do público celíaco a uma maior variedade de preparos. Além disso, a araruta favorece o estímulo econômico e a propagação cultural para as comunidades tradicionais que mantém a plantação deste rizoma, bem como a redução do risco de extinção desta planta.

\section{Referências}

lbuquerque, M. D., \& Pinheiro, E. (1970). Tuberosas feculentas. Embrapa Amazônia Oriental-Séries anteriores (INFOTECA-E).

Barufaldi, M. (2021) Araruta: a farinha esquecida pelos brasileiros. www.diariodemarilia.com.br/Noticias/121533/Araruta-a-farinha-esquecida-pelosbrasileiros Brasil. Ministério da Agricultura, Pecuária e Abastecimento. (2013). Manual de hortaliças não-convencionais (99p). Mapa/ACS.

Castro, T. V. (2018). Análise sensorial do pão sem glúten elaborado a base da farinha de araruta enriquecido com bagaço da farinha de laranja.

Cetra. (2021). CETRA - Centro de Estudos do Trabalho e de Assessoria ao Trabalhador. https://cetra.org.br/

Chitarra, M. I. F., \& Chitarra, A. B. (2005). Pós-colheita de frutos e hortaliças: fisiologia e manuseio (p. 320). Esal/Faepe.

Coelho, I. D. S., Santos, M., Almeida, D. L. D., Silva, E. M. R. D., \& Neves, M. (2005). Como plantar e usar a araruta. Embrapa Informação Tecnológica; Seropédica, RJ: Embrapa Agrobiologia

Corrêa, M. P. (1984). Dicionário das plantas úteis do Brasil e das exóticas cultivadas: HL (Vol. 4). Ministério da Agricultura, Instituto Brasileiro de Desenvolvimento Florestal

Costa, F. R. C., Espinelli, F. B., \& Figueiredo, F. O. G. (2008) Guia de Marantaceas da Reserva Duke e da Reserva Biológica do Uatumã (J. J. Roper, Trad.).: INPA

Ferrari, T. B., Leonel, M., \& Sarmento, S. B. S. (2005). Características dos rizomas e do amido de araruta (Maranta arundinacea) em diferentes estádios de desenvolvimento da planta. Brazilian Journal of Food Technology, 8(2), 93-98.

Fernandes, L. E. S., \& Nascimento, C. F. (2020). Araruta-uma espécie quase esquecida, da produção a alimentação: conservação da agrobiodiversidade nativa. Cadernos de Agroecologia, 15(2).

Kay, D. E. (1973). Root crops (No. 633.4/K23). Tropical Products Institute.

Kinupp, V. F., \& Lorenzi, H. J. (2014). Plantas Alimentícias Não Convencionais (PANC) no Brasil: guia de identificação, aspectos nutricionais e receitas ilustradas

Lana, M. J. M. D. P., Souza, M. R. D. M., Santos, D. C. L., Pinto, C. M. F., \& Pinto, C. L. D. O. (2020). Mercado de hortaliças não convencionais em feiras de São Cristóvão-SE. Cadernos de Agroecologia, 15(2) 
Research, Society and Development, v. 10, n. 15, e387101522776, 2021

(CC BY 4.0) | ISSN 2525-3409 | DOI: http://dx.doi.org/10.33448/rsd-v10i15.22776

Leonel, M., \& Cereda, M. P. (2002). Caracterização físico-química de algumas tuberosas amiláceas. Food Science and Technology, 22(1), 65-69.

Leonel, M., Jackey, S., \& Cereda, M. P. (1998). Processamento industrial de fécula de mandioca e batata doce-um estudo de caso. Food Science and Technology, $18(3), 343-345$.

Manohar, R., Rao, P., Manohar, R., \& Rao, P. (1999). Effect of mixing method on the rheological characteristics of biscuit dough and the quality of biscuits. European Food Research And Technology, 210(1), 43-48. 10.1007/s002170050530

Melo, M. S. D. B. (2019). Mandioca, batata-doce e araruta como matérias primas para obtenção de amidos fosfatados.

Mesa, L. D. R. M. (2011). Dissertação no Mestrado em Engenharia Mecânica. Estudo da pirólise de cana-de-açúcar integral

Monteiro, D. A., Peressin, V. A (2002). Cultura da araruta. In: M. P. Cereda (Eds.), Agricultura: tuberosas amiláceas Latino Americanas (2a ed.), 440-447. Fundação Cargill.

Neves, M. C. P., Coelho, I. D. S., \& de Almeida, D. L. (2005). Araruta: Resgate de um cultivo tradicional. Embrapa Agrobiologia-Comunicado Técnico (INFOTECA-E).

Nogueira, G. F., Fakhouri, F. M., \& de Oliveira, R. A. (2018). Extraction and characterization of arrowroot (Maranta arundinaceae L.) starch and its application in edible films. Carbohydrate polymers, 186, 64-72.

Porto, A., (2021). Portal Tudo Sobre Plantas | Enciclopedia Botânica Online. [online] Portal Tudo Sobre Plantas. <https://www.tudosobreplantas.com.br/> [acesso 15 May 2021].

Rodrigues, L. B. O. (2014). Estudos reológicos e de textura dos géis de amido de araruta (Maranta arundinaceae L.) e dos géis adicionados de sacarose e concentrado protéico de soro (Dissertação de Mestrado em Engenharia e Ciência de Alimentos). (2014). Universidade Estadual do Sudoeste da Bahia, Itapetinga.

Shafizadeh, F. (1982). Introduction to pyrolysis of biomass. Journal of analytical and applied pyrolysis, 3(4), $283-305$.

Silva, J. R. S., \& Monteiro, D. A. (1968). Cultura da araruta industrial. O Agronômico, 20 (11/12), 11 - 21.

Silva, P. V. B. (2021). Sistema agroindustrial do milho crioulo livre de transgênico no território da borborema. (Trabalho de conclusão de curso, Universidade Federal da Paraíba, Areia, PB). Recuperado de https://repositorio.ufpb.br/jspui/handle/123456789/14814

Singh, N., Singh, J., Kaur, L., Sodhi, N. S., \& Gill, B. S. (2003). Morphological, thermal and rheological properties of starches from different botanical sources. Food chemistry, 81(2), 219-231.

Souza, D. C. D., Lima, L. F., Resende, L. V., Costa, P. A., Guerra, T. S., Gonçalves, W. M., \& Pereira, T. A. R. (2017). Conservação pós-colheita de araruta em função da temperatura de armazenamento. Magistra, 28(3/4), 403-410

Tester, R. F., \& Morrison, W. R. (1990). Swelling and gelatinization of cereal starches. I. Effects of amylopectin, amylose, and lipids. Cereal chem, 67(6), 551557.

Tester, R. F. (1997). Starch: the polysaccharide fractions. Starch: structure and functionality. Royal Society of Chemistry

Thomas, D. J., \& Atwell, W. (1999). Practical guides the food industry in starch.: Eagan.

Wei, M., Liu, Y., Liu, B., Lv, X., Sun, P., Zhang, Z., \& Liu, Z. (2011). Preparation and application of starch phosphate with a low degree of substitution. Phosphorus, Sulfur, and Silicon and the Related Elements, 186(4), 974-982.

Wang, X., Reddy, C. K., \& Xu, B. (2018). A systematic comparative study on morphological, crystallinity, pasting, thermal and functional characteristics of starches resources utilized in China. Food chemistry, 259, 81-88.

Zárate, N. A. H., \& Vieira, M. D. C. (2005). Produção da araruta'Comum'proveniente de três tipos de propágulos. Ciência e Agrotecnologia, 29(5), 995-1000. 